\title{
PERCEPÇÃO AMBIENTAL DE VISITANTES DA RPPN SERRA DAS ALMAS, CRATEÚS/CE: A ESCOLHA DA ESPÉCIE GUARDA-CHUVA COMO POTENCIAL EDUCATIVO E DE GESTÃO
}

\author{
Iris Rianne Santana Alves ${ }^{1}$ \\ Gilson Miranda do Nascimento ${ }^{2}$ \\ Paulo Sérgio Maroti ${ }^{3}$
}

\section{Resumo}

Este trabalho se baseia em Dietz e Nagagata (1997) que propõe o direcionamento de programas em educação conservacionista aos visitantes e comunidades do entorno das áreas protegidas utilizando-se de espécies que proporcionam rápida identificação com as pessoas, também chamados de espécies guarda-chuva. Partindo da ideia do uso de espécies guarda-chuva como forma de contribuir para a conservação, foram utilizados questionários como ferramenta para o estudo da percepção de visitantes (professores e público variado) quanto a possível espécie que poderia ser símbolo da RPPN. Os questionários (67) foram aplicados entre os meses de agosto à dezembro de 2010, período caracterizado como de extrema seca. Os resultados obtidos foram: I) quanto ao perfil do visitante: a) referente ao gênero (67\% mulheres) e faixa etária (entre 16 a 25 anos); b) procedência (33\% Crateús/CE, 43\% Fortaleza/CE e 24\% Buriti dos Montes/PI); c) formação: professores com formação diversificada (pedagogia, ciências biológicas e química). Os resultados obtidos para a espécie guarda-chuva para a área foram: a) espécies botânicas: plantas xerófilas e bromeliáceas, juazeiro (Ziziphus joazeiro). b) espécies da fauna: macaco-prego (Cebus apella). Vale destacar que, dos entrevistados, $75 \%$ desconheciam a área e o animal mais preferido (macaco-prego) era de fácil visualização em uma das trilhas da RPPN. Tais resultados possibilitam o uso didático da espécie escolhida junto aos visitantes e população do entorno visando se estimular a biofilia, buscando estabelecer aspectos perceptivos e de sensibilidade ambiental na referida comunidade. O resultado da percepção para a definição de uma espécie guarda-chuva foi confirmado com a literatura especializada quanto a maior preferência por espécies antropomórficas e que despertam sentimento de compaixão, neste caso o primata (Cebus apella). Logo podemos refletir à respeito dos benefícios da escolha de uma espécie guarda-chuva pode trazer à gestão de uma UC, principalmente para a questão de uso público e do potencial educativo.

Palavras-chave: Biofilia; Espécie Guarda-Chuva; Percepção.

\footnotetext{
Abstract

This work is based on Dietz and Nagagata (1997) suggests that the targeting of conservation education programs for visitors and communities around protected areas using species that provide rapid identification with people, also called umbrella species. Based on the idea of using umbrella species as a way to contribute to the conservation

1 Graduada, Licenciatura em Ciências Biológicas/Universidade Federal de Sergipe. - Email: irisrianne@gmail.com

2 Graduando em Ciências Biológicas. Faculdade de Educação de Crateús (FAEC), Universidade Estadual do Estado do Ceará, UECE.

3 Biólogo, Doutor em Ecologia e Recursos Naturais. Prof. Adjunto da Universidade Federal de Sergipe - Email: dpsm@ufs.br
} 
questionnaires were used as a tool to study the perception of visitors (teachers and varied audience) as the possible species that could be symbol of RPPN. The questionnaires (67) were applied between the months of August to December 2010, a period characterized as extreme drought. The results were: I) as the visitor profile: a) related to gender (67\% female) and age (between 16-25 years), b) origin (33\% Cratéus / CE, 43\% Fortaleza / CE and 24\% of Montes Buriti / PI) c) training: teachers with diverse background (education, biological sciences and chemistry). The results for umbrella species for the area were: a) botanical species: plants and bromeliads xerófilas, juazeiro (Ziziphus joazeiro). b) the animal species: capuchin monkey (Cebus apella). It is noteworthy that, of the respondents, $75 \%$ did not know the area and the animal most preferred (capuchin monkey) was identifiable in one of the tracks of RPPN. These results allow the didactic use of chosen species with visitors and the surrounding population in order to stimulate the biophilia, seeking to establish perceptual aspects and sensitivity environment in that community. The result of perception to the definition of an umbrella species were confirmed by the literature as the most preferred species by anthropomorphic and that arouse feelings of compassion, in this case the primate (Cebus apella). Soon we can reflect on about the benefits of choosing an umbrella species can bring to the management of a UC, especially on the issue of public use and educational potential.

Keywords: Biophilia; Umbrella Species; Perception, 


\section{Apresentação do tema}

Quando se pretende tocar no assunto das áreas naturais protegidas, a educação, no caso da educação denominada ambiental, devendo permear, sustentar ou ser à base das ações da gestão desses espaços. Vários são os trabalhos que lidam a temática e a educação ambiental (EA) tenta nesses anos de construção e lapidação se aproximar deste tema, tendo como base para a discussão a corrente naturalista que segundo Sauvé (2012) é a mais antiga, além da conservacionista/recursista, a resolutiva e a sistêmica. Para a primeira, a "educação para o meio natural" e "educação ao ar livre" a autora menciona Steve Van Matre como o nome referência desta linha e que propõe a "educação para a terra". A segunda, talvez a que mais define esse trabalho, pode ser sintetizada pela "conservação da natureza" e na "administração do meio ambiente" ou gestão ambiental. A terceira, a de resolver questões e problemas ambientais e por último, a busca do conhecimento e compreensão das realidades e problemáticas ambientais. Acreditamos ser estas linhas que norteiam esse trabalho e as enquadramos, como Sauvé, entre as correntes mais tradicionais da EA, não deixando de se aproximar, dentre as correntes vanguardistas: a prática, a da eco-educação e da sustentabilidade.

A percepção ambiental, que também pauta esse trabalho, segue as ideias da ecologia da percepção de James J. Gibson que propõe o conceito de affordance ou tudo aquilo que o ambiente oferece ao observador (Santaella, 2012, p.56). Affordance é impossível de ser traduzido. O verbo é afford, grosseiramente traduzido por "oferecer", mas o substantivo não existia antes de Gibson inventa-lo. O que o ambiente oferece? O que uma trilha interpretativa oferece ao visitante, ao escolar? A resposta de Gibson, segundo Santaella op. Cit., é talvez uma composição e o layout das superfícies constituem-se no que elas ofertam. A percepção implica um ambiente significativo revelando-se para o percebedor. As affordances são portanto os significados dos traços do ambiente e que influenciam o observador que se sujeita a percorrer caminhos naturais em áreas naturais protegidas.

Além da ecologia da percepção de Gibson, a ecologia da paisagem também servirá de sustentação para as nossas discussões, referenciada pelo ecólogo Fernando Gonsalez BernaldezequeBenayas (1994,p. 21) define como um conjunto de processossubjetivos determinado pelas diferentes formas dever einterpretar o mundobaseado nasinter-relações entre o homem e a paisagem, justificando suas atitudes sobre o meio ambiente.

Quanto a RPPN “Serra das Almas” (RPPN SA), esta encontra-se no bioma caatinga, sendo mais bem definido como "As Caatingas", conforme o Serviço Florestal Brasileiro (2010). Uma vez que trata-se de um conjunto de mosaicos compostos por arbustos espinhosos e florestas sazonalmente secas e por apresentarem a característica de perder suas folhas durante o período de estiagem. Abrangem a maior parte dos estados da região Nordeste e da parte nordeste do estado de Minas Gerais, ou seja 10\% do território nacional. Apesar de ser uma região semiárida, com índices pluviométricos baixos (entre 300 e $800 \mathrm{~mm}$ por ano), a caatinga é extremamente heterogênea. Apresenta vegetação lenhosa caducifólia espinhosa (savana estépica). Domina as terras baixas do complexo cristalino e vertentes com chuvas de serra e chapadas distantes do litoral. As florestas semidecíduas e decíduas (matas secas) ocorrem nas vertentes a 
interior da área semiárida. (SFB,2010)

Segundo Major et al. (2004) o bioma caatinga apresenta um baixo investimento dirigido à conservação, isso porque as UCs pertencentes à categoria de proteção integral do Brasil, onde não é permitida nenhuma forma de exploração direta, equivalendo a 3\% do território nacional, sendo que apenas $4 \%$ desta área estão localizadas no bioma caatinga. Apenas $1 \%$ de sua área tem proteção integral, o que corresponde a 1.084.516 ha. Estes autores destacam que a distribuição destas áreas protegidas não é uniforme, uma vez que $94 \%$ da superfície protegida é de domínio público e $6 \%$ de domínio privado. Comparando com o nível nacional, onde apenas $2 \%$ da área são protegidas por privados, mostrando assim a maior importância da conservação em terras privadas neste bioma.

Dados do Cadastro Nacional de RPPNs (2013) mostram que a mata atlântica supera a caatinga em número de reservas (Tabela 1), indicando descaso na manutenção da biodiversidade deste bioma. $\mathrm{Na}$ área da educação, destaca-se à carência de recursos didáticos para serem utilizados na sensibilização da população quanto à importância desse bioma único e de suas quase inexistentes áreas protegidas.

\begin{tabular}{|l|c|c|c|c|c|}
\hline \multicolumn{1}{|c|}{ Bioma } & $\begin{array}{c}\text { Número } \\
\text { de RPPN }\end{array}$ & Área (ha) & $\begin{array}{c}\text { Área Mé- } \\
\text { dia (ha) }\end{array}$ & $\begin{array}{c}\text { \% das } \\
\text { reservas }\end{array}$ & \% da Área \\
\hline Caatinga & 54 & 80506,85 & 1490,87 & $5,0 \%$ & $11,4 \%$ \\
\hline Pantanal & 24 & 267870,95 & 11161,29 & $2,2 \%$ & $38,1 \%$ \\
\hline Pampa & 8 & 3169,66 & 396,21 & $0,7 \%$ & $0,5 \%$ \\
\hline Amazônia & 50 & 42586,49 & 851,73 & $4,6 \%$ & $6,1 \%$ \\
\hline Cerrado & 193 & 166406,45 & 862,21 & $17,8 \%$ & $23,7 \%$ \\
\hline $\begin{array}{l}\text { Mata Atlân- } \\
\text { tica }\end{array}$ & 743 & 141238,90 & 190,09 & $68,7 \%$ & $20,1 \%$ \\
\hline Costeiro & 10 & 1344,90 & 134,49 & $0,9 \%$ & $0,2 \%$ \\
\hline Total & 1082 & 703124,20 & 649,84 & & \\
\hline
\end{tabular}

Tabela 1: Sumarização das RPPN's por bioma

Fonte: http://www.reservasparticulares.org.br/relatorios

As áreas naturais que apresentam um grau de equilibro são capazes de nos beneficiar com o fornecimento do que chamamos de funções ou serviços ambientais.

Segundo De Groot apud Junior (2003, p. 61), os componentes ambientais estão subdivido de acordo com as funções ambientais (Tabela 2): de produção, de suporte, de informação e de regulação, sendo estes componentes fornecidos pelos ecossistemas de acordo com seu estado de conservação, ou seja, quanto maior for o estado de conservação da área, maior serão os benefícios desfrutados pelas comunidades. Entretanto, percebe-se que essa discussão ainda esta restrita ao meio acadêmico e, dificilmente atravessa tais muros. Daí a importância no processo de popularização e disseminação de tais conceitos junto às comunidades do entorno das áreas protegidas. 


\begin{tabular}{|l|l|l|l|}
\hline $\begin{array}{c}\text { FUNÇÕES DE RE- } \\
\text { GULAÇÃO }\end{array}$ & $\begin{array}{l}\text { FUNÇÕES DE SU- } \\
\text { PORTE }\end{array}$ & $\begin{array}{l}\text { FUNÇÕES DE PRO- } \\
\text { DUÇÃO }\end{array}$ & $\begin{array}{l}\text { FUNÇÕES DE } \\
\text { INFORMA- } \\
\text { ÇãO }\end{array}$ \\
\hline 1. Regulação climática & $\begin{array}{l}\text { 10.Recreação/aqüi- } \\
\text { cultura } \\
\text { /silvicultura/ Agri- } \\
\text { cultura. }\end{array}$ & $\begin{array}{l}\text { 12. Recursos gené- } \\
\text { ticos. }\end{array}$ & 15. Estética \\
\hline $\begin{array}{l}\text { 2. Prevenção de inun- } \\
\text { dação. }\end{array}$ & $\begin{array}{l}\text { 11. Proteção da } \\
\text { natureza }\end{array}$ & $\begin{array}{l}\text { 13. Recursos medi- } \\
\text { cinais }\end{array}$ & $\begin{array}{l}\text { 16. Científica e } \\
\text { educacional }\end{array}$ \\
\hline $\begin{array}{l}\text { 3. Prevenção à Erosão/ } \\
\text { sedimentar }\end{array}$ & $\begin{array}{l}\text { 14. Matéria prima } \\
\text { para } \\
\text { Construção civil e } \\
\text { trabalhos } \\
\text { Artesanais }\end{array}$ & \\
\hline $\begin{array}{l}\text { 4. Fixação bioenergé- } \\
\text { tica }\end{array}$ & & & \\
\hline $\begin{array}{l}\text { 5. Armazenamento } \\
\text { reciclagem de nutrien- } \\
\text { tes e M.O. }\end{array}$ & & & \\
\hline $\begin{array}{l}\text { 6. Estoque e reci- } \\
\text { clagem de Efluentes in- } \\
\text { dustriais e domésticos }\end{array}$ & & & \\
\hline $\begin{array}{l}\text { 7. Controle biológico } \\
\text { Reprodução }\end{array}$ & & & \\
\hline $\begin{array}{l}\text { 9. Manutenção da } \\
\text { Biodiversidade }\end{array}$ & & & \\
\hline
\end{tabular}

Tabela 2: Funções ambientais e seus dezesseis componentes ambientais (modificado de JUNIOR, 2003).

Dessa maneira a caatinga, apesar dos valorosos serviços ambientais prestados à sociedade, é concebida como o "primo pobre" dos biomas brasileiros. Como forma de contribuir com a conservação dessas áreas e consequente manutenção desses serviços, têm sido utilizado as espécies guarda-chuva, que segundo BENSUSAN (2006a, p. 133) corresponde a espécie cuja conservação garante a manutenção de outras, ou seja, assegurar a sobrevivência dessas espécies permite a integridade do ambiente onde ele vive e dos organismos que interagem com ela, contribuindo dessa forma para a conservação de todo o ecossistema. Esta autora informa que métodos de designação de espécies guarda-chuva como indicador da existência de significativa biodiversidade tem sido bastante utilizado em programas de educação conservacionista e atividades de sensibilização das comunidades e visitantes das áreas protegidas.

A Educação Ambiental (EA) ao estimular a compreensão, participação e envolvimento das pessoas em processos que busquem o bem comum (ambiental e social), torna-se uma ferramenta importante para a conservação de áreas protegidas, comumente ameaçadas. A adoção de abordagens participativas como diagnósticos 
consultivos, corresponde então ao elemento primordial em programas de EA no incentivo de populações próximas dessas áreas para tê-los como aliados na conservação. (PADUA, TABANEZ e SOUZA, 2004, p.558)

Este trabalho se baseia em Dietz e Nagagata (1997) que propõe o direcionamento de programas em educação conservacionista aos visitantes e comunidades do entorno das áreas protegidas utilizando-se de espécies que proporcionam rápida identificação com as pessoas, também chamados de espécies guarda-chuva.

Partindo do exposto este trabalho buscou determinar, utilizando-se da percepção de visitantes da RPPN Serra das Almas, a espécie símbolo da área ou guarda-chuva, subsidiando ações na gestão da área (Programa de Educação e Interpretação Ambiental - Uso Público).

\section{Metodologia}

A RPPN SA está localizada no município de Crateús/CE, no semi-árido nordestino. Esta unidade de conservação (UC), Sistema Nacional de Unidades de Conservação - SNUC - (Lei n. 9.985/2000), pertencente à categoria de Uso Sustentável (Associação Caatinga, 2007).

A carnaúba (Copernicia cerífera) foi considera árvore símbolo da RPPN devido ao seu uso doméstico na região. Em setembro de 1935 o americano Herbert F. Johnson Junior, saindo dos Estados Unidos para o Brasil em uma viagem denominada "Expedição Carnaúba", a fim de conhecer esse país e encontrar riquezas em terras brasileiras chegou ao Ceará e percebeu que a comunidade local utilizava uma espécie de pó, extraído das folhas mais jovens da carnaúba (palmeira nativa do nordeste brasileiro) e quando utilizado no assoalho das casas, ficava lustroso. Percebendo a potencialidade daquele "pó" ele construiu sua riqueza industrializando esse produto e que atualmente possui significativos usos (JOHNSON, 1998).

Em agradecimento as pessoas da região sertaneja e ao bioma caatinga, seu filho Samuel C. Johnson formalizou em 1996 um projeto que seu pai sonhava, destinando as terras da propriedade para a conservação na forma de RPPN. Por esse motivo, a carnaúba foi escolhida inicialmente para espécie símbolo deste projeto.

Cabe destacar que, de maneira alguma através desse trabalho buscou-se desprestigiar a história construída sobre o recurso natural da carnaúba e as inter-relações com as pessoas do local. Pretendeu-se, à partir do caminhar do projeto da RPPN e do crescimento da demanda de visitantes, dar a oportunidade da escolha da espécie símbolo do seu usuário.

A RPPN “Serra das Almas” faz limites com os municípios de Crateús/Ceará e Buriti dos Montes/Piauí (Figura 1). Ela também possui três trilhas destinadas à visitação, à saber: Trilha dos Macacos, Lajeiro e Arapucas, sendo que as duas primeiras apresentam $1,5 \mathrm{~km}$ e a última possui $6,5 \mathrm{~km}$ de distância. Todas elas com nível de dificuldade leve. 


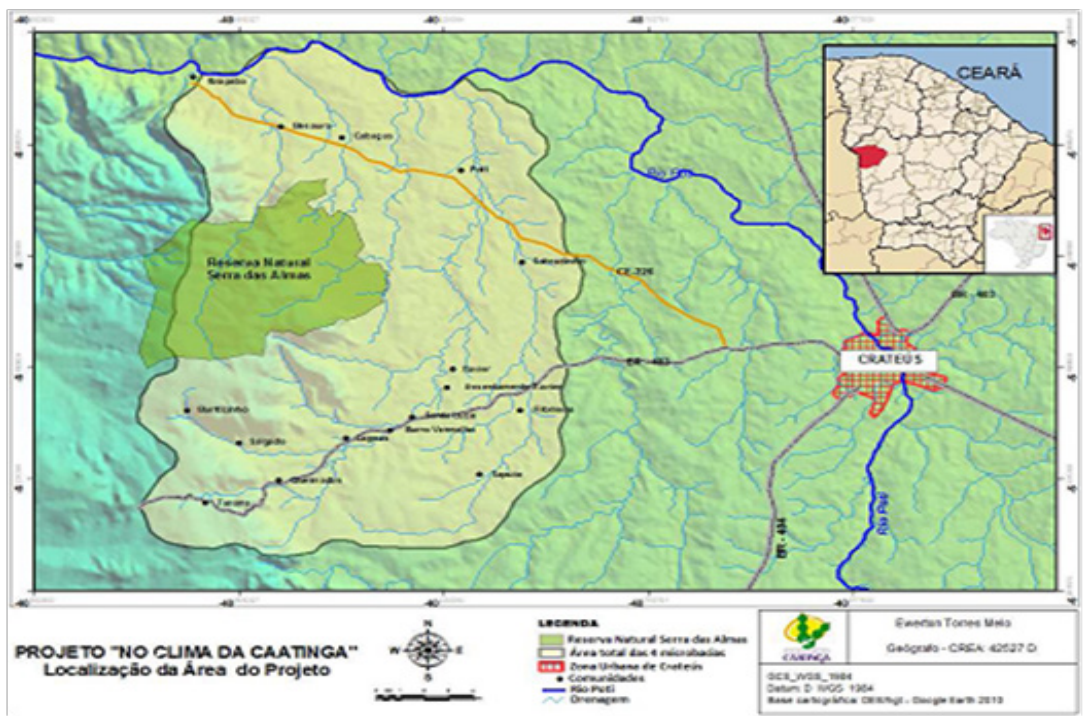

Figura 1: Delimitação da Reserva Natural Serra das Almas e seu entorno. (Associação Caatinga, 2010.)

Dessa forma foi elaborado um questionário semi-estruturado (14 questões), que segundo Minayo (2004, p. 108) apud Rocha e Araújo (2007) combina perguntas fechadas (ou estruturadas) e abertas, no qual, o entrevistado tem a possibilidade de discorrer o tema proposto.

O questionário foi aplicado a sessenta e sete visitantes e permitiu levantamento do perfil, sua avaliação sobre a visita à reserva (perguntas fechadas) e a escolha da espécie guarda-chuva (pergunta aberta) da RPPN SA. Entretanto para este artigo serão descritas análises das questões que se referem a espécie guarda-chuva e o perfil dos visitantes, pois as demais questões fizeram parte da avaliação da estrutura física da reserva e de seus funcionários (qualidade do refeitório e atividade dos guarda-parques).

Considerando a pergunta chave desta pesquisa visando a compreensão e análise ("Que símbolo poderia representar a Reserva Natural Serra das Almas?") foram criadas categorias, tendo como artifício os símbolos mais citados nos questionários, sendo eles: plantas xerófilas, macaco-prego (Cebus apella), onça parda (Puma concolor), o juazeiro (Ziziphus joazeiro), carnaúba e outros (répteis, animais domésticos, etc).

Cabe destacar que o questionário segundo Pimbert e Petty (1997) apud Bensusan (2006b, p. 133) é um dos meios pelo qual estimula a participação da comunidade, pois são fornecidas informações que podem contribuir na gestão de áreas protegidas, desde que seus resultados não sejam banalizados.

Após os dados obtidos, estes foram posteriormente tabulados e analisados utilizando-se do programa Excel da Microsoft. 


\section{Discussões e resultados}

Verificou-se dentro do perfil dos visitantes amostrados na pesquisa foi de maioria feminino (67\%), com idade variando de 16 a 25 anos com $78 \%$ e residindo nos municípios de Crateús/CE (33\%), Fortaleza/CE (43\%) e Buriti dos Montes/PI (24 $\%$ ). Estes dados revelam o interesse para a visitação de um público mais distante da área (Fortaleza) do que do público mais próximo.

Entre o público participante da pesquisa também estavam professores do ensino básico com formação diversificada (pedagogia, ciências biológicas e química).

Entre os visitantes estiveram presentes alunos de instituições de ensino básico e superior, para o desenvolvimento de roteiro turístico e atividades de pesquisa/escolar. Para este grupo, observou-se que $84 \%$ dos participantes estavam interessados na pesquisas do que no turismo.

Entre os participantes da pesquisa a maior parte deles (75\%) informou nunca ter feito visita à reserva, enquanto $25 \%$ disseram já ter isso à reserva, sendo que entre os que já disseram já ter visitado esta UC, correspondem aos estudantes de graduação e população das comunidades limítrofes.

A reserva possui dentro de seus limites três trilhas destinadas a interpretação ambiental. Nessa pesquisa, do público amostrado 39\% utilizou da trilha do lajeiro, $47 \%$ a trilha dos macacos, isso pode ser explicado pelo fato de serem trilhas de pequena extensão (ambas com $1500 \mathrm{~m}$ ) o que facilita os visitantes fazerem os dois percursos a cada visita. Outro fator estimulante refere-se ao corpo d'água existente (recurso quase inexistente nas regiões do entorno e portanto muito valorizada durante a visitação). O crescente uso destas trilhas tem causado maior impacto como o seu alargamento e exposição de rochas e raízes de árvores trazendo sérias consequências de erosão e perda da biota do solo.

A Trilha das Arapucas, frequentada por 14\% do grupo participante da pesquisa, talvez por possuir maior extensão de área $(6500 \mathrm{~m})$ apesar de não possuir o corpo d'água em seu percurso compensa o esforço do trilheiro com bela visão panorâmica.

Quanto aos resultados obtidos referente ao símbolo que poderia representar a RPPN "Serra das Almas", foram divididos entre fauna e flora (Figura 2). Coube destaque para a flora: as plantas xerófilas/plantas nativas (cactáceas e bromeliáceas) característica desse bioma, ficaram com $31 \%$ e o juazeiro (Ziziphus joazeiro) com $7 \%$. Para a fauna, o macaco-prego (Cebus apella) foi escolhido por $25 \%$, sendo o mais preferido e a onça-parda (Puma concolor) com 14\%. Na categoria "outros", destaca-se os répteis com as cobras e lagartos (Iguana iguana); roedores (cutia - Dasyprocta azarae); aves como o carcará (Caracara plancus) e o urubu- rei (Sarcoramphus papa). Ainda no item "outros" da questão, foram citadas exemplares da flora como a Cajazeira (Spondias mombin) e a Mangueira (Mangifera indica), apesar desta última não pertencer ao bioma caatinga. Destaca-se que a primeira espécie símbolo da reserva, a carnaúba, contou com $3 \%$ de escolha. 


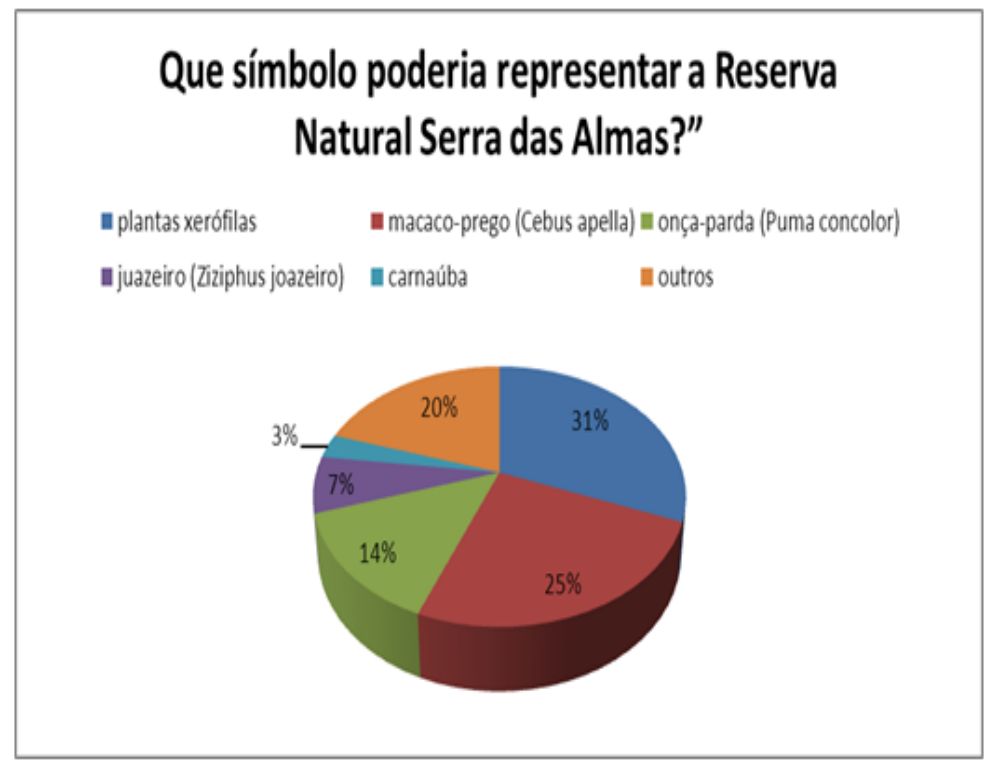

Figura 2: Resultados referente a pergunta "Que símbolo poderia representar a Reserva Natural Serra das Almas?”

No que se refere a espécie guarda-chuva, entre as mais citadas, cabe destaque para a indicação das plantas xerófilas como o mandacaru, cactos e bromélias, que é tida como representante do bioma, talvez esse tenha sido o fato do número de citação superior aos demais, além de que a Trilha do Lajeiro, a segunda mais visitada, é facilmente visualizados essas espécies. O macaco-prego (Cebus apella) foi a segunda espécie mais citada como possível representante da RPPN "Serra das Almas", essa explicação se dá pelo fato da constante presença desse animal na trilha que recebe seu nome, isso pode ser verificado observando que na maioria dos questionários que indica essa espécie havia feito a visita a esta trilha.

Quanto à percepção para a definição de uma espécie guarda-chuva foi confirmado dados já constatados na literatura especializada quanto a uma maior preferência por espécies antropomórficas e que despertam sentimento de compaixão, neste caso o primata (Cebus apella).

O juazeiro, a terceira espécie dentre os símbolos da flora mais percebidas ou com significativa affordance, pode estar relacionada ao fato da guia da trilha durante o percurso ter relatado aos visitantes uma lenda típica intitulada "Como a caatinga passou a esconder sua beleza" (Maia, 2004, p.90). A lenda pode ter despertado a atenção e comoção para muitos visitantes quanto a este belo exemplar da flora sertaneja, o que significou um destaque simbólico e determinante na percepção.

O fato da Carnaúba não ter sido percebida pelos os visitantes e a comunidade local, já que essa espécie apresentou um dos menores valores quando comparados a outras espécies, pode evidenciar a relativa eficiência da metodologia adotada em programas de educação conservacionista uma vez que leva em conta somente a riqueza faunística e florística, sem antes verificar como ou qual seria a espécie mais para a comunidade. 
pesquisa, tendo certa afinidade dos visitantes ao primata denotando sentimento biofílico. Dessa forma a utilização de espécies que despertam a biofilia apresenta grande potencial estratégico de efetivação da conservação em áreas protegidas, já que contribuem no processo de sensibilização com a comunidade limítrofe e demais visitantes, conforme afirma literatura especializada (Tuan, 1982; WILSON, 1993).

Cabe destacar que a aproximação da população à ambientes naturais está relacionada à biofilia, que diz respeito à uma necessidade intrínseca e inata do ser humano de estar em contato com a natureza (WILSON, 1993). Para este mesmo autor os seres humanos apresentam uma necessidade genética de base evolucionária, a se associarem profunda e intimamente aos ambientes naturais, particularmente ao meio biótico (animais e plantas) no sentido de promoção de saúde física e emocional, além da satisfação pessoal (WILSON, 1984 apud ABDALA, 2002, p.25).

\section{Considerações finais}

Segundo Maroti (2002, p.17) alguns programas de educação ambiental implantados em UC's que tiveram sucesso utilizaram programas conservacionistas dirigidos a espécies guarda- chuva para atrair a atenção da comunidade de entorno, além da obtenção de apoio público com a finalidade da preservação dos habitats associados às espécies em questão.

Temos como exemplo de efetivação de programas conservacionistas o Projeto Tamar (2013), que utiliza as tartarugas marinhas como forma de manter a qualidade ambiental da costa brasileira distribuídas entre várias UCs, além do Projeto Micoleão-dourado na Reserva Biológica de Poço das Antas e Reserva Biológica União, ambas localizadas no Rio de janeiro, somando-se a outras categorias de UCs (RPPNs e APAs) buscam esforços para a conservação desta espécie guarda-chuva (NUNES et al, s.d.).

Embora alguns desses programas do uso de espécies guarda-chuva se mostrem eficazes do ponto de vista da manutenção dos recursos naturais e seus serviços ambientais eles tratam os problemas e aspectos conceituais com certa externalidade, pois no momento da escolha da espécie muitas vezes não há consulta à população, dificultando para a comunidade do entorno a assumir tais valores estimulados pelos programas (MAROTI, 2002, p.17).

Podemos refletir a respeito dos benefícios que um levantamento prévio de uma espécie guarda- chuva pode trazer à gestão de uma UC, contribuindo para que a comunidade inicialmente reconheça o papel de determinada espécie para áreas protegidas e como consequência colaborarem com a manutenção dos serviços ambientais.

A partir deste levantamento da percepção dos visitantes sobre a espécie símbolo ou guarda-chuva da reserva, será possível a utilização destes resultados para a elaboração de um Programa de Educação Ambiental (uso público), que não informe apenas, mas que permita a população "conhecer para conservar". Como sugerem Padua, Ta- 
banez e Souza (2004, p.559) que a adoção de abordagens participativas, voltadas para populações próximas de área naturais, permite se envolver na conservação e proteção destas.

Quanto às questões metodológicas da ecologia da percepção e da paisagem, nota-se que o símbolo oferecido ao visitante, ou o affordance, foram determinantes para as escolhas dos símbolos da referida área. Momentos, como o caso da fácil visualização de uma espécie (como o caso do Macaco-Prego) durante a realização da trilha, ou mesmo a presença da água (percepção da hidrofilia) (Benayas op. Cit.) para a escolha do trajeto pelo visitante em uma ambiente árido fizeram a diferença em nossos resultados. Seguindo as práticas utilizadas pelo Projeto de Ecoturismo do IDSM (Instituto de Desenvolvimento Sustentável Mamiraúa) na Reserva Amaná AM (Coelho \& Osório, 2011), onde os guias monitoram as escolhas e visualizações dos visitantes durante o trajeto nas trilhas utilizando-se de planilhas com espécies perceptíveis. O mesmo poderia ser adotado para as trilhas da RPPN SA, visando à adoção de novas espécies perceptíveis durante os anos vindouros de atividades educativas. Fica evidenciado que, a percepção e os affordances são dinâmicos e que, de alguma forma, nosso espaço percebido muda de acordo com períodos do ano, público diferenciado e a detalhes da paisagem.

\section{Referências}

ABDALA, G. C. Uma abordagem socioecológica do Parque Nacional de Brasília - estudo de caso. Cadernos UNESCO Brasil. Série Meio Ambiente (4). Brasília: UNESCO, 2002. 82p.

ASSOCIAÇÃO CAATINGA. No clima da caatinga. Petrobras Ambiental, 2010.

ASSOCIAÇÃO CAATINGA, Plano de Manejo da RPPN Serra das Almas: 2007$20112^{\circ}$ interação. Fortaleza, 2007.

BENAYAS, J. La percepción del paisaje. In: Guía Didáctica para interpretar y actuar sobre el paisaje. 1994, 20- 26 p.

BENSUSAN, N.; BARROS, A. C.; BUlHÕES, B.; ARANTES, A. (Orgs.). Biodiversidade: para comer, vestir ou passar no cabelo? São Paulo: Petrópolis; Brasília: IEB. 2006a.418p.

BENSUSAN, N. Conservação da biodiversidade em áreas protegidas. Rio de Janeiro: Editora FGV, 2006b. 176p.

BRASIL. Lei 9.985, de 18 de julho de 2000. Dispõe sobre o SNUC - Sistema Nacional de Unidades de Conservação. Brasília, 2000. 
Coelho, E.A. \& Ozório, R.Z. O processo de planejamento e envolvimento com o turismo de base comunitária na Reserva Amaná - AM. In: IV Encontro Interdisciplinar de Ecoturismo em Unidades de Conservação. São Paulo, Caderno de Resumos, p. 576, 2011.

DIETZ, L.A. \& NAGAGATA, E.Y. Programa de Conservação do Mico-Leão-Dourado: atividades de educação comunitária para a conservação da mata atlântica no Estado do Rio de Janeiro. In: Tabanez, M.F. (org). Educação Ambiental - caminhos trilhados no Brasil. Brasilia; Ipê - Instituto de Pesquisas Ecológicas, 133-146, 1997.

JOHNSON, Jr. 1998. Expedição Carnaúba. A história de uma aventura científica, de aviação, para estudar a palmeira da Carnaúba em sua origem, no interior do Brasil. Tradução do original "Carnauba Expedition", publicada em 1936 com a colaboração de A. Dailey. Fortaleza: Ed. Esteves- Tiprogresso/ Fundação Waldemar Alcântara/ TNC. $135 p$.

JUNIOR, A. F. O. Valoração Econômica da Função Ambiental de Suporte relacionada às atividades de turismo, Brotas, SP . 2003. 277p. Tese de Doutorado, PPGERN (UFSCar), São Carlos.

MAIA, G. N. Caatinga: árvores e arbustos e suas utilidades. 1ª ed. São Paulo: D\&Z. 2004. (p.90- 94)

MAJOR, I.; JUNIOR, L.G.S.; CASTRO, R. Aves da Caatinga. Fortaleza: Edições Demócrito Rocha, Associação Caatinga, 2004.

MAROTI, P.S. Educação e Interpretação Ambiental junto à comunidade do entorno de uma Unidade de Conservação. 2002. 178p. Tese de Doutorado. PPGERN, UFSCar, São Carlos.

NUNES, A. L. et al. O mico-leão-dourado ( leontopitecus rosalia ) - um raro produto para o ecoturismo e a conservação da mata atlântica. 1-10p. s.d. Disponivel em: www.physis.org.br/ecouc/Artigos/Artigo40.pdf Acessado e 21 de Abril de 2013.

PADUA, S. M., TABANEZ, M.F., SOUZA, M.G. A abordagem participativa na educação para a conservação da natureza. In: Métodos de Estudos em Biologia da Conservação e Manejo da Vida Silvestre. 2a . ed. Editora UFPR, 2006. 557- 591 p.

PROJETO TAMAR. Disponível em < www.tamar.org.br/>. Acessado em 25 de abril de 2013.

ROCHA, M. M. V.; ARAÚJO, E. A. Competência informacional e atuação do profissional da informação - bibliotecário. In: VIII ENANCIB - Encontro Nacional de Pesquisa em Ciência da Informação. 2007. 14p. Disponível em: http://www.enancib. ppgci.ufba.br/artigos/GT6--028.pdf

SATO, M., CARVALHO, I.C.M. Educação Ambiental. Artmed, 2005. 
SERVIÇO FLORESTAL BRASILEIRO. Florestas do Brasil em resumo - 2010: dados de 2005-2010. Brasília: SFB, 2010.

Sumarização das RPPN’s por bioma. Disponível em <http://www.reservasparticulares.org.br/relatorios/>. Acessado em 25 de abril de 2013.

WILSON, E.O. Biophilia and the conservation ethic. In: Kellert, S.R. \& Wilson, E.O. (eds). The biophilia hipothesis. Washington, Island Press, p. 31-41, 1993. 